Please do not remove this page

RMIT

UNIVERSITY

\title{
Pt/SnO2 nanowires/SiC based hydrogen gas sensor
}

Shafiei, Mahnaz; Wlodarski, Wojciech; Kalantar Zadeh, Kourosh; Comini, E.; Bianchi, Salvadore; Sberveglieri, G.

https://researchrepository.rmit.edu.au/esploro/outputs/9921863474401341/filesAndLinks?institution=61RMIT_INST\&index=null

Shafiei, M., Wlodarski, W., Kalantar Zadeh, K., Comini, E., Bianchi, S., \& Sberveglieri, G. (2007). Pt/SnO2 nanowires/SiC based hydrogen gas sensor. IEEE Sensors 2007, 166-169.

https://doi.org/10.1109/ICSENS.2007.4388362

Published Version: https://doi.org/10.1109/ICSENS.2007.4388362

Repository homepage: https://researchrepository.rmit.edu.au

(c) 2007 IEEE. Personal use of this material is permitted. However, permission to reprint/republish this material for advertising or promotional purposes or for creating new collective works for resale or redistribution to servers or lists, or to reuse any copyrighted component of this work in other works must be obtained from the IEEE.

Downloaded On 2023/04/26 20:25:40 +1000 


\section{$\mathrm{Pt} / \mathrm{SnO}_{2}$ Nanowires/SiC Based Hydrogen Gas Sensor}

\author{
M. Shafiei, W. Wlodarski, and K. Kalantar-zadeh \\ RMIT University, City Campus, GPO Box 2476V, \\ Melbourne 3001, Victoria, AUSTRALIA \\ Email:mahnaz@ieee.org
}

\author{
E. Comini, S. Bianchi and G. Sberveglieri \\ SENSOR INFM-CNR University of Brescia, \\ via Valotti 9, Brescia, Italy \\ Email: Comini@tflab.ing.unibs.it
}

\begin{abstract}
P t} / \mathrm{SnO}_{2}$ nanowires/SiC based metal-oxidesemiconductor (MOS) devices were fabricated and tested for their gas sensitivity towards hydrogen. Tin oxide $\left(\mathrm{SnO}_{2}\right)$ nanowires were grown on $\mathrm{SiC}$ substrates by the vapour liquid solid growth process. The material properties of the $\mathrm{SnO}_{2}$ nanowires such as its formation and dimensions were analyzed using scanning electron microscopy (SEM). The currentvoltage $(I-V)$ characteristics at different hydrogen concentrations are presented. The effective change in the barrier height for 0.06 and $1 \%$ hydrogen were found to be 20.78 and $131.59 \mathrm{meV}$, respectively. A voltage shift of $310 \mathrm{mV}$ at $530^{\circ} \mathrm{C}$ for $1 \%$ hydrogen was measured.
\end{abstract}

\section{INTRODUCTION}

Recently, the interests in nanostructured materials have been increased because they often show novel physical and chemical properties which are different from those displayed by their bulk counterparts [1-3]. They are more stable when they operate at high temperatures for a long time. The electrical properties of the polycrystalline materials alters due to grain coalescence, porosity modification and grainboundary alteration [1]. In 1991, Yamazoe [2] reported that the reduction in size of the crystallite caused a huge enhancement in gas sensor performance. Nanostructured materials such as semiconducting metal oxide nanoparticles, nanowires and nanorods have been widely used for gas sensing applications because of their large surface to volume ratio [3,4]. Examples of such materials include: $\mathrm{SnO}_{2}$ nanobelts for $\mathrm{CO}$ and $\mathrm{NO}_{2}$ [5], $\mathrm{In}_{2} \mathrm{O}_{3}$ nanowires for $\mathrm{NO}_{2}$ [6], $\mathrm{WO}_{3}$ nanowires for $\mathrm{NO}_{2}$ [7], and $\mathrm{TiO}_{2}$ nanotubes for $\mathrm{H}_{2}$ [8]. The increase in the surface of nanostructured materials also causes surface effects which leads to increase in catalytic activity or surface adsorption. Therefore, the extension of the surface exposed to gas adsorption makes improvement in the sensitivity of the materials.

$\mathrm{SnO}_{2}$ is an n-type semiconductor with a wide band gap $(3.6 \mathrm{eV})$ and is extensively used for applications including gas sensing, electrochemical or photoelectrochemical-based energy conversion [9, 10], anti-static films and antireflecting coatings in solar cells [11]. $\mathrm{SnO}_{2}$ has been widely utilized for gas sensing applications due to its suitable physicochemical properties including high stability and reactivity to reducing gases such as hydrogen [12]. When $\mathrm{SnO}_{2}$ is exposed to different gas species, the material's resistance changes because of the charge carrier exchange between the adsorbed gas and the oxide surface [13]. Hence, the gas sensing properties of $\mathrm{SnO}_{2}$ depend on its surface structure.

There are a number of reports in literature dealing with the gas sensing applications of nanostructured $\mathrm{SnO}_{2}$. Zhang et al. [14] has conducted experiments with $\mathrm{SnO}_{2}$ single nanowires sensor in a FET structure for different gases including oxygen and $\mathrm{CO}$. Room temperature sensing properties of a single crystalline $\mathrm{SnO}_{2}$ nanowire sensor towards nitrogen dioxide has also been investigated by Law et al. [9]. Other experiments were carried out by Lou et al. [15] on nanostructured $\mathrm{SnO}_{2}$-based gas sensors. They prepared $\mathrm{SnO}_{2}$ nanomaterials by three different methods: chemical precipitation, sol-gel and dissolution-pyrolysis. They also conducted gas sensing measurements and reported that the $\mathrm{SnO}_{2}$-based sensor prepared by dissolution-pyrolysis method has high sensitivity, quick response and recovery to different gases. $\mathrm{Li}$ et al. [16] also have developed $\mathrm{SnO}_{2}$ nanoparticles gas sensors. They reported that the $\mathrm{SnO}_{2}$ nanoparticles have high sensitivities towards reducing gases.

$\mathrm{SiC}$ is a semiconducting material with a wide band gap of $3.2 \mathrm{eV}$ which is suitable for high temperature gas sensing [17]. To date, gas sensors based on metal-oxide-SiC have been investigated [18-20]. By using metal oxide in between the substrate and the catalytic metal, selectivity, sensitivity and stability of the such sensors can be increased [21].

In this paper, we present gas sensing properties of the devices combining transition metals such as platinum and nanostructured metal oxide $\left(\mathrm{SnO}_{2}\right)$ with $\mathrm{SiC}$ operating at high temperatures. The microstructural characteristics and development of the sensor using the vapour liquid solid growth method to grow $\mathrm{SnO}_{2}$ nanowires have been demonstrated. We have investigated the hydrogen gas sensing performance for an operating temperature in the range of $300-650^{\circ} \mathrm{C}$. We have also studied the barrier height changes for different concentrations of hydrogen gas obtained from the $I-V$ measurements.

\section{EXPERIMENTAL}

The $\mathrm{Pt} / \mathrm{SnO}_{2}$ nanowires/SiC based MOS devices were fabricated using n-type $6 \mathrm{H}-\mathrm{SiC}$ wafer. The $\mathrm{SiC}$ wafers were diced into $3 \mathrm{~mm} \times 3 \mathrm{~mm}$ squares. The thickness of the $\mathrm{SiC}$ 
wafer was approximately $250 \mu \mathrm{m}$. A circular pad of Pt and Ti metal layers with $1 \mathrm{~mm}$ diameter was deposited on the unpolished side of the wafer by sputtering. This side forms the ohmic contact after high temperature annealing. The thickness of the Pt and $\mathrm{Ti}$ are $100 \mathrm{~nm}$ each. Consequently, the $\mathrm{SnO}_{2}$ nanowires were deposited by the vapour liquid solid growth mechanism on the polished side of the $\mathrm{SiC}$ samples. Platinum was used as a growth catalyst. Small platinum clusters were dispersed on the $\mathrm{SiC}$ substrate by sputtering and the as prepared substrates were placed in the tubular furnace together with the source $\mathrm{SnO}_{2}$ powder. The oxide is placed at $1370^{\circ} \mathrm{C}$ while the $\mathrm{SiC}$ substrates at temperatures between 450 and $500^{\circ} \mathrm{C}$. The deposition takes place at 100 mbar with a flux of $75 \mathrm{sccm}$ of Ar as gas carrier. A circular pad of platinum with diameter of $1 \mathrm{~mm}$ was deposited on the nanostructured metal oxide by sputtering to form a Schottky contact. After fabricating the devices, they were annealed in air at $450^{\circ} \mathrm{C}$ for 4 hours and at $600^{\circ} \mathrm{C}$ for 2 hours.

The sensor was placed in the chamber with an alumina micro-heater in close contact, to control its operating temperature. The gas sensing measurements were conducted in a computerized multi channel gas calibration system, which allows different concentrations of the analyte gas including hydrogen and propene to be exposed to the sensor. Concentrations in the range of 0.06 to $1 \%$ of hydrogen and propene were introduced in the test chamber at constant volumetric gas flow rate of $200 \mathrm{ml} / \mathrm{min}$.

The $I-V$ measurements were carried out using a Keithley 2602 current sourcemeter to investigate the effective change in the barrier height due to exposure to the different concentrations of hydrogen. Since the change in the Schottky barrier height results in the alteration of the voltage-current characteristics, the response of the sensor was measured as the shift in voltage when the sensor was biased at a constant current. The voltage shift was recorded using an Agilent 34410A multimeter.

\section{RESULT AND DISCUSSION}

\section{A. Material Characterization}

The nanowires have a very high aspect ratio as the length exceeds several microns and the width is smaller than $100 \mathrm{~nm}$, and they are uniformly dispersed on the substrate. A SEM image of $\mathrm{SnO}_{2}$ nanowires is shown in Fig. 1.

High resolution TEM and electron diffraction showed that the wire is single crystalline, with atomically-sharp termination of lateral sides. Bragg reflections and the whole symmetry of the ED pattern agree with the cassiterite tetragonal $\mathrm{SnO}_{2}$ phase (P42/mnm-SG 136). The direction of the electron beam is parallel to the [010] zone-axis of the reciprocal lattice and the nanowire grows along to the [100] direction [22] .

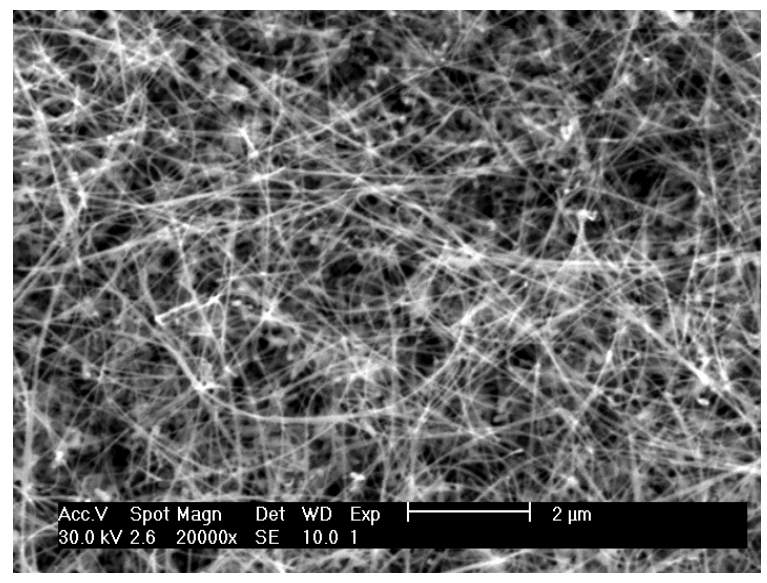

Figure 1. SEM image of $\mathrm{SnO}_{2}$ nanowires

\section{B. Electrical Properties}

From Fig. 2 the sensor shows the highest sensitivity towards different hydrogen concentrations at $530^{\circ} \mathrm{C}$ (e.g. the voltage shifts for $0.5 \%$ hydrogen were 145,189 and $150 \mathrm{mV}$ at 420,530 and $620^{\circ} \mathrm{C}$, respectively). Therefore, $530^{\circ} \mathrm{C}$ was chosen as an operating temperature. The forward and reverse $I-V$ characteristics of the device towards different hydrogen concentrations $(0.06,0.125,0.25,0.5$, and $1 \%)$ at $530^{\circ} \mathrm{C}$ are highlighted in Fig. 3. Information regarding the change in the barrier heights is extracted from these $I-V$ curves. The lateral shift in the $I-V$ characteristics is due to changes in barrier height. The changes in slope in the linear portion of the characteristics are because of the change in the series resistance resulting from a decrease in the metal oxide resistance.

Based on the thermionic emission theory [23] the following equation is often used for the $I-V$ characteristics of the Schottky diode:

$I=I_{s}\{\exp (q V / n k T)-1\}$

where $k$ is Boltzmann's constant, $T$ is the temperature in Kelvin, $n$ is the ideality factor which expresses the effect of a non-ideal Schottky diode and $I_{S}$ is the saturation current:

$I_{s}=S A * * T^{2} \exp \left(-q \phi_{B} / k T\right)$,

where $S$ is the diode area, $A^{* *}$ is the effective Richardson's constant and $\phi_{B}$ is the barrier height. The saturation current was obtained from (1) and the barrier height was calculated from (2). 


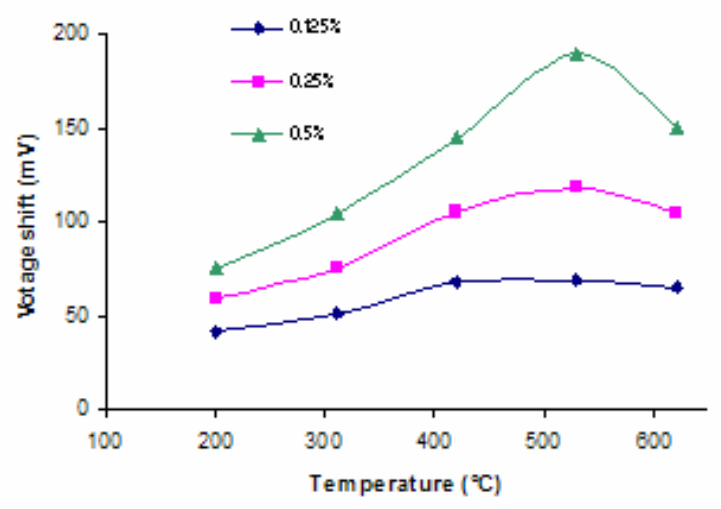

Figure 2. Voltage shifts at different temperatures vs different hydrogen gas concentrations

The effective changes in the barrier heights when the sensor was exposed to different hydrogen concentrations are illustrated in Fig. 4. It was found that in synthetic air at $530^{\circ} \mathrm{C}$, the saturation current and the barrier height were $0.838 \mathrm{nA}$ and $2.04 \mathrm{eV}$, respectively. When the sensor was exposed to $1 \%$ hydrogen, the saturation current and the barrier height changed to $6.84 \mathrm{nA}$ and $1.90 \mathrm{eV}$, respectively. Obviously, the magnitude of the barrier height shift increases with the increase of hydrogen concentrations. Trinchi et al. [24] have also reported that the barrier height of $\mathrm{Pt} / \mathrm{Ga}_{2} \mathrm{O}_{3} / \mathrm{SiC}$ based hydrogen gas sensors increases with the increase of hydrogen concentrations.

(a)
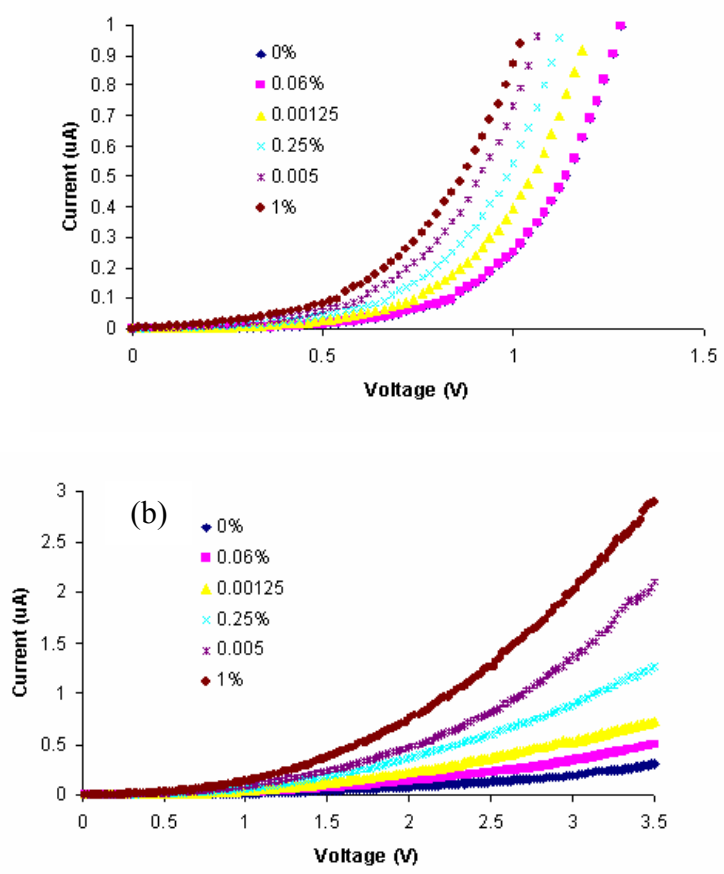

Figure 3. a) Forward $I-V$ and b) reverse $I-V$ characteristics of the $\mathrm{Pt} / \mathrm{SnO}_{2}$ nanowires/ $\mathrm{SiC}$ sensor towards different hydrogen gas concentrations at $530^{\circ} \mathrm{C}$

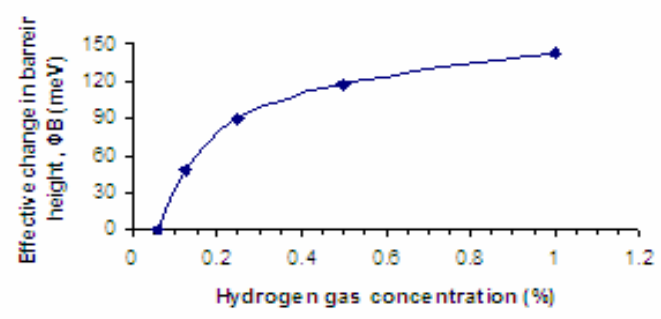

Figure 4. Change in barrier height for different hydrogen concentrations at $530^{\circ} \mathrm{C}$.

\section{Gas Response Performance}

The dynamic response of the device towards different concentrations of hydrogen at $530^{\circ} \mathrm{C}$ is shown in Fig. 5 . Voltage shifts of 95 and $310 \mathrm{mV}$ for 0.25 and $1 \%$ hydrogen were recorded at $530^{\circ} \mathrm{C}$, respectively. Kandasamy et al. [19] have reported the voltage shifts of 30 and $80 \mathrm{mV}$ for 0.25 and $1 \%$ hydrogen, respectively for $\mathrm{Pt} / \mathrm{WO}_{3} / \mathrm{SiC}$ devices at $530^{\circ} \mathrm{C}$.

The sensor was also tested towards propene. From Fig. 6 the sensitivity to $0.125 \%$ propene at $530^{\circ} \mathrm{C}$ was found to be 1.79 times higher than that of hydrogen. Consequently, the sensor is more promising for hydrocarbons gas sensing.

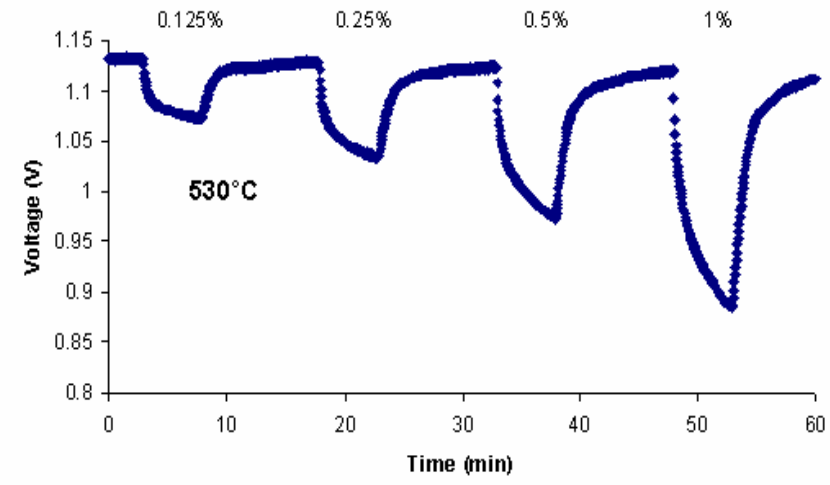

Figure 5. Dynamic response characteristics of the $\mathrm{Pt} / \mathrm{SnO}_{2}$ nanowire/SiC device towards hydrogen $(0.12,0.25,0.5$, and $1 \%)$ at $530^{\circ} \mathrm{C}$.

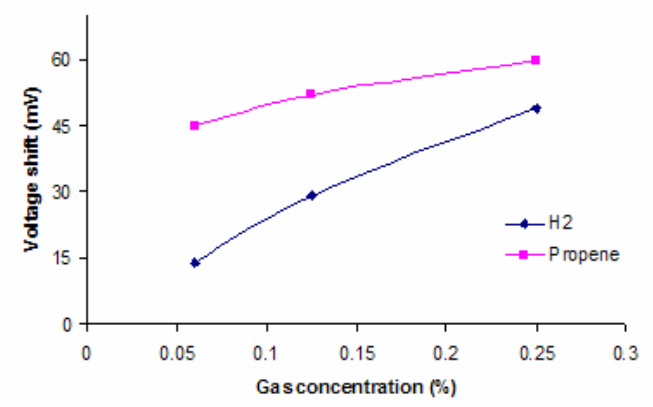

Figure 6. Voltage shifts at different concentrations of hydrogen and propene at $530^{\circ} \mathrm{C}$. 


\section{CONCLUSION}

We have developed the $\mathrm{Pt} / \mathrm{SnO}_{2}$ nanowires/SiC sensors and tested their sensing properties towards gaseous hydrogen at high temperatures. The morphological characteristics of the nanostructured thin films and electrical characteristics of the devices were investigated. In addition, we have studied the influence of the different gas concentrations and temperatures on the barrier height of the devices. We have also tested the devices' gas sensing towards propene at $530^{\circ} \mathrm{C}$. The results show that the sensitivity of the devices towards propene is higher than to hydrogen. Hence, these devices are very promising for hydrocarbons gas sensing.

\section{REFERENCES}

[1] E. Comini, "Metal oxide nano-crystals for gas sensing," Analytica Chimica Acta Molecular Electronics and Analytical Chemistry, vol. 568, pp. 28-40, 2006.

[2] N. Yamazoe, Sensor Acutators B, vol. 5, p. 7, 1991.

[3] C. Baratto, E. Comini, G. Faglia, G. Sberveglieri, M. Zha, and A. Zappettini, "Metal oxide nanocrystals for gas sensing," Sensors and Actuators B: Chemical E-MRS Fall Meeting - Nanostructured materials and nanotechnologies for new chemical sensors and alternative energy devices., vol. 109, pp. 2-6, 2005.

[4] E. Comini, V. Guidi, C. Malagu, G. Martinelli, Z. Pan, G. Sberveglieri, and Z. L. Wang, "Electrical Properties of Tin Dioxide Two-Dimensional Nanostructures," J. phys. Chem. B, vol. 108, pp. 1882-1887, 2004.

[5] E. Comini, G. Faglia, G. Sberveglieri, Z. Pan, and Z. L. Wang, "Stable and highly sensitive gas sensors based on semiconductiong oxide nanobelts," Appl. Phys. Lett, vol. 81, pp. 1869-1871, 2002.

[6] D. Zhang, Z. Liu, C. Li, T. Tang, X. Liu, S. Han, B. Lei, and C. Zhou, "Detection of $\mathrm{NO}_{2}$ down to ppb levels using individual and multiple $\mathrm{In}_{2} \mathrm{O}_{3}$ nanowire devices," NanoLetters, vol. 4, no. 10, pp. 1919-1924, 2004.

[7] K. M. Sawicka, A. K. Prasad, and P. I. Gouma, "Metal oxide nanowires for use in chemical sensing applications," Sensor Lett., vol. 3, no. 1, pp. 1$5,2005$.

[8] H. Y. Dang, J. Wang, and S. S. Fan, "The synthesis of metal oxide nanowires by directly heating metal samples in appropriate oxygen atmospheres," Nanotechnology, vol. 14, pp. 738-741, 2003.

[9] M. Law, H. Kind, B. Messer, F. Kim, and P. Yang, Angew. Chem. Int. Ed, vol. 41, p. 2405, 2002.

[10] A. Kolmakov and Y. Zhang, Advanced Materials, vol. 15, pp. $997-$ 1000, 2003.

[11] E. S. R. S.I. Rembeza, T.V. Svistova, O.I. Borsiakova,, "Electrical Resistivity and Gas Response Mechanisms of Nanocrystalline SnO Films in a Wide Temperature Range," phys. stat. sol. (a), vol. 179, pp. 147-152, 2000.

[12] V. Demarne and R. Sanjine, Gas Sensors, edited by G. Sberveglieri (Kluwer Academic Publishers, Netherlans, 1992), p. 89.

[13] U. Hoefer and J. Frank, Sensors And Actuators B, vol. 78, pp. 6-11, 2001.

[14] Y. Zhang, A. Kolmakov, H. Metiu, and M. Moskovits, Nanoletters, vol. 4, p. 403, 2004.
[15] X. Lou, C. Peng, X. Wang, and W. Chu, "Gas-sensing properties of nanostructured $\mathrm{SnO}_{2}$-based sensor synthesized with different methods," Vacuum, vol. In Press, Corrected Proof.

[16] F. Li, J. Xu, X. Yu, L. Chen, J. Zhu, Z. Yang, and X. Xin, "One-step solid-state reaction synthesis and gas sensing property of tin oxide nanoparticles," Sensors and Actuators B: Chemical, vol. 81, pp. 165-169, 2002.

[17] A. Lloyd, P. Tobias, A. Baranzahi, P. Martensson, and I. Lundstrom, "Current status of silicon carbide based high-temperature gas sensors," Electron Devices, IEEE Transactions on, vol. 46, pp. 561-566, 1999.

[18] A. Trinchi, W. Wlodarski, and Y. X. Li, "Hydrogen sensitive $\mathrm{GA}_{2} \mathrm{O}_{3}$ Schottky diode sensor based on SiC," Sensors and Actuators B, vol. 100, pp. 94-98, 2004.

[19] S. Kandasamy, A. Trinchi, W. Wlodarski, E. Comini, and G. Sberveglieri, "Hydrogen and hydrocarbon gas sensing performance of Pt/WO3/SiC MROSiC devices," Sensors and Actuators B: Chemical

Eurosensors XVIII 2004 - The 18th European Conference on Solid-State Transducers, vol. 111-112, pp. 111-116, 2005.

[20] S. Nakagomi, K. Okuda, and Y. Kokubun, "Electrical properties dependent on $\mathrm{H} 2$ gas for new structure diode of Pt-thin WO3-SiC," Sensors and Actuators B: Chemical, vol. 96, pp. 364-371, 2003.

[21] G. W. Hunter, P. G. Neudeck, M. Gray, D. Androjna, L.-Y. Chen, R. W. H. Jr., C. C. Liu, and Q. H. Wu, "SiC-based gas sensor development," Mater. Sci. Forum 338-342 (part 2), pp. 1439-1442, 2000.

[22] G.Sberveglieri, C.Baratto, E.Comini, G. Faglia, M.Ferroni, A. Ponzoni, and A. Vomiero, "Synthesis and characterization of semiconducting nanowires for gas sensing," Sensors and Actuators B vol. 121, pp. 208-213, 2007.

[23] S. M. Sze, "Physics of Semiconductor Devices," second ed, Wiley, New York, 1981.

[24] A. Trinchi, W. Wlodarski, Y. X. Li, G. Faglia, and G. Sberveglieri, "Pt $/ \mathrm{Ga}_{2} \mathrm{O}_{3} / \mathrm{SiC}$ MRISiC devices: a study of the hydrogen response," J. phys. D: Appl. Phys, vol. 38, pp. 754-763, 2005. 